\title{
The incidence, risk factors, and outcomes of acute kidney injury in the intensive care unit in Sudan
}

\author{
Salma Mohammed Magboul ${ }^{1} \cdot$ Bashier Osman $^{2} \cdot$ Asim Ahmed Elnour $^{3}$ (i)
}

Received: 3 January 2020 / Accepted: 5 September 2020 / Published online: 20 September 2020

(c) Springer Nature Switzerland AG 2020

\begin{abstract}
Background There is a paucity of studies in acute kidney injury in the intensive care unit, particularly in Sudan. Objectives The current study has estimated the incidence; risk factors and outcomes of subjects with acute kidney injury developed during admission to the intensive care unit at Fedail Hospital, Khartoum, Sudan. Methodology This was a cross-sectional study conducted in the intensive care unit during the period from July 2018 to June 2019. The data was collected from the clinical profiles of all adult subjects' who have met the published criteria for acute kidney injury. Analysis of association (Chi square test $\chi^{2}$ ) and multivariate logistic regression were used to analyze data. Main outcome measure The development of acute kidney injury during the subjects' stay in the intensive care unit, length of hospital stay and death. Results From a total of 187 subjects admitted to the intensive care unit; only $(105,56.2 \%)$ have met the inclusion criteria (mean age was $61 \pm 3.5$ years). The main finding of the study was the high incidence of acute kidney injury $39 \%$. The major significant predictors for the development of acute kidney injury with respective odds ratio (OR) were: sepsis (OR 7.5 [95\% CI 3-19.7]; $P$ .001 ); hypovolemia (OR 5.1 [95\% CI 2-15.7]; $P$.001); chronic cardiovascular diseases (OR 3.4 [95\% CI 1.2-9.4]; $P$.017); age > 60 years (OR 2.7 [95\% CI 1.2-6.3]; $P$.018); diabetes mellitus (OR 2.6 [95\% CI 1.2-6]; $P$.02); hypertension (OR 2.4 [95\% CI 1.2-5.4]; $P$.028); and renal replacement therapy (OR 0.2 [95\% CI 0.15-0.3]; $P$.001). The length of hospital stay within the AKI cohort was $(6.7 \pm 3.8$; [range 2-17]) and the mortality rate was $(36,87.8 \%)$. Conclusion The major significant predictors for the development of acute kidney injury in the intensive care unit were: sepsis; hypovolemia; chronic cardiovascular diseases; age > 60 years; diabetes mellitus; hypertension; and renal replacement therapy. Sepsis and hypovolemia were common etiologies for acute kidney injury post-admission to the intensive care unit. Acute kidney injury was associated with increased length of hospital stay and a very high absolute mortality rate.
\end{abstract}

Keywords Acute kidney injury (AKI) $\cdot$ Intensive care unit $\cdot$ Mortality $\cdot$ Renal replacement therapy $\cdot$ Risk factors

$\begin{array}{ll}\text { Abbreviations } \\ \text { ACE } & \text { Angiotensin-converting enzyme } \\ \text { ARBs } & \text { Angiotensin receptor blockers } \\ \text { AKD } & \text { Acute kidney diseases } \\ \text { AKI } & \text { Acute kidney injury (AKI) } \\ \text { CI } & \text { Confidence interval } \\ \text { ESRF } & \text { End-stage renal failure } \\ \text { ICU } & \text { Intensive care units }\end{array}$

Asim Ahmed Elnour

assahura2020@gmail.com

1 College of Pharmacy, Al Neelain University, Khartoum, Sudan

2 Department of Pharmacology, Faculty of Pharmacy, University of Khartoum, Khartoum, Sudan

3 Clinical Pharmacy Program, College of Pharmacy, Al Ain University (AAU), Abu Dhabi, UAE
KDIGO Kidney Disease Improving Global Outcomes

NSAIDs Non-steroidal anti-inflammatory drugs

OR Odds ratio

RRT Renal replacement therapy

SD Standard deviation

SEA Southeast Asia

SPSS Statistical package for social science software

SSC Surviving Sepsis Campaign

\section{Impacts on practice}

- Identifying the risk factors for the development of acute kidney injury will assist healthcare professionals in implementing preventive strategies. 
- Prevention strategies will decrease hospital length of stay and will improve short-term survival.

- The stratification of subjects admitted to the intensive care unit for the risk of acute kidney injury should be based on their susceptibilities and exposures.

- The increased mortality of subjects with acute kidney injury has an impact on the population health outcomes.

- The presence of the clinical pharmacist within the intensive care unit will assist in early stratifying subjects with acute kidney injury and will ensure the implementation of the protocol.

\section{Introduction}

The clinical guidelines from Kidney Disease Improving Global Outcomes (KDIGO) define acute kidney injury (AKI) as a subgroup of acute kidney diseases (AKD) and disorders, and classify AKI according to severity (stages) and cause, which impacts both prognosis and management [1]. The clinical outcome of AKI involves morbidity (chronic kidney disease [CKD] and end-stage renal failure [ESRF]), mortality, and considerable cost to population health [1]. Globally, AKI affects over 13 million people per year and results in 1.7 million deaths [2, 3]. Four in five cases of AKI occur in the developing world [2, 3]. Geographical, etiological, cultural, and economic reasons may underlie potential disparities in the risk of AKI between and within higher and lower-income countries.

In a systematic review (cohort studies) of AKI, was conducted to estimate the world incidence of AKI and its stages of severity and associated mortality, and to describe geographic variations according to countries, regions, and their economies. The pooled incidence rate of AKI was 21.6\% (95\% confidence interval [CI], 19.3-24.1\%); with $10 \%$ required dialysis and with the highest rate in critical care settings (32\%) [4]. Other studies, in subjects admitted to the hospital, one-third of AKI cases were hospital-assimilated $[5,6]$.

AKI is diagnosed in up to $20 \%$ of hospitalized subjects [5], and in $30-60 \%$ of critically ill subjects $[7,8]$. AKI is the most frequent cause of organ dysfunction in intensive care units (ICUs) and the occurrence of even mild AKI is associated with a $50 \%$ higher risk of death [9]. AKI results in a significant burden for the society in terms of health resource use during the acute phase, and the potential longterm sequelae including the development of CKD and kidney failure in ICU $[10,11]$. The International Society of Nephrology has called the nephrology and the broader health care community to work collaboratively to develop effective programs to stem the tide of preventable deaths due to untreated AKI in developing countries. The " 0 by 25 " initiative has been launched with a goal that no one should die of untreated AKI by 2025 [12].

\section{Rationale}

Despite the consensus in the definition of AKI, there are still huge variations in its incidence and the associated risk factors. Therefore, exploring the variations in the risk of AKI will assist in understanding the contributory common risk factors and the confounders.

\section{Objectives}

The current study has estimated the incidence; risk factors and outcomes of subjects with AKI developed during admission to the ICU at Fedail Hospital, Khartoum, Sudan.

\section{Ethics approval}

The study protocol was approved by the Faculty of Pharmacy Research Board (Research Ethics Committee, No. 1/4/2018), at the Faculty of Pharmacy, Khartoum University-Sudan. Consent was provided by all subjects and informed confidentiality and anonymity of participant' information has been assured.

\section{Methods}

This was a cross-sectional study conducted within the ICU during the period from July 2018 to June 2019. The data was collected from the clinical profiles of all adult subjects' who have met the published criteria for AKI. The inclusion criteria were: $>18$ years; not presenting with AKI at admission to the ICU, and developed AKI during ICU stay period. The following subjects were excluded: subjects with kidney transplantation or organ donors, subjects with prior CKD or ESRF, and subjects who were readmitted to the ICU.

The total numbers of subjects admitted to ICU at Fedail hospital during the study period were 187 . The total numbers of subjects who have met the inclusion criteria were 105. This was illustrated in a diagram including the number of subjects who have developed AKI (Fig. 1).

The diagnosis of AKI was based on the rise in serum creatinine and/or fall in urine output. The KDIGO staging for the severity of AKI was used to classify the different three stages of AKI ("Appendix 1"). According to changes in the serum creatinine and the urine output, AKl has been classified by various criteria such as the Risk, Injury, Failure, Loss, and End-stage renal disease (RIFLE), AKI Network (AKIN), and Kidney Disease Improving Global Outcomes (KDIGO) ("Appendix 2"). The definitions of AKI were included in "Appendix 3". 

subjects admitted to the ICU during the study period. $A K I$ sive care unit, $E S R D$ end stage renal disease
Fig. 1 Descriptive diagram for Acute kidney injury, ICU inten-
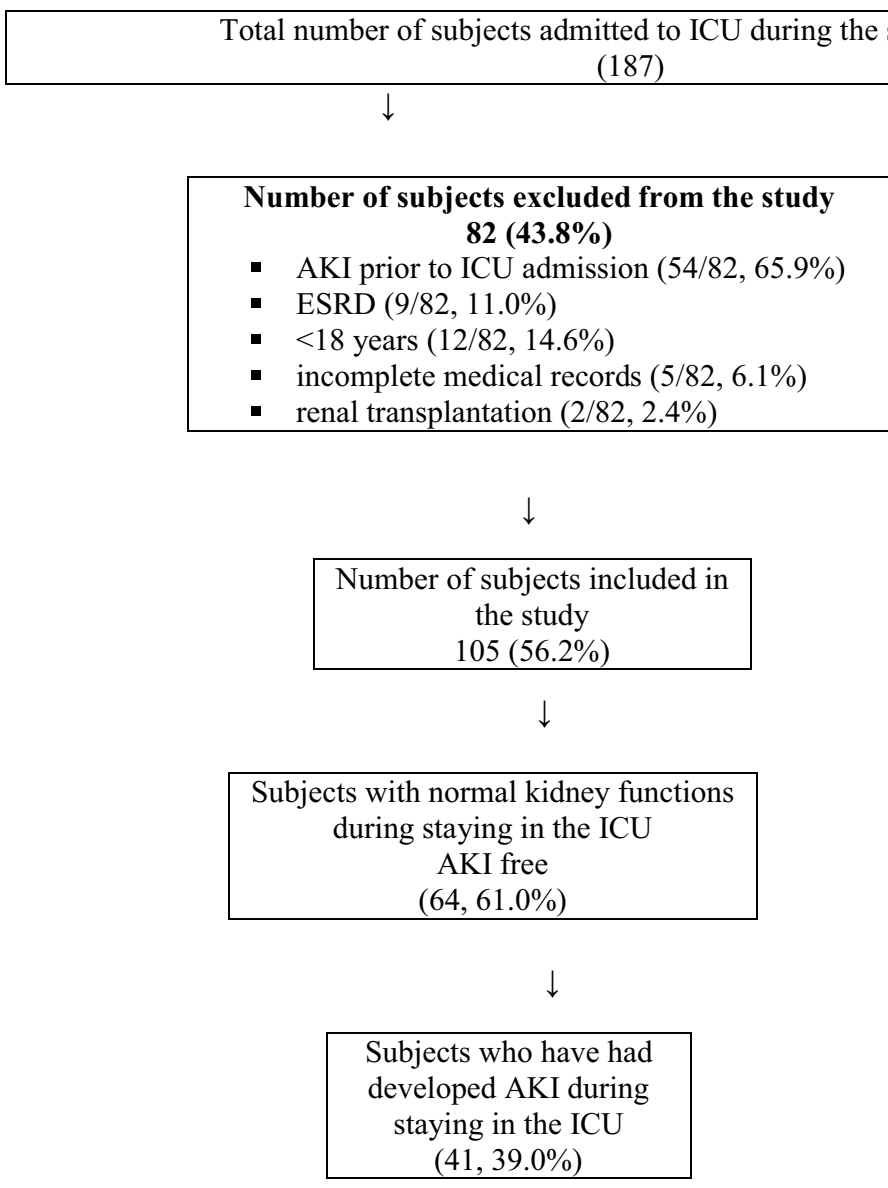

The clinical practice guidelines for AKI set by the Kidney Disease Improving Global Outcomes (KDIGO) were used for defining and staging the severity of AKI [1]. Our hospital uses published clinical practice guidelines for severe sepsis and septic shock. This criterion was set by the Surviving Sepsis Campaign (SSC) for the management of severe sepsis and septic shock [13].

\section{Statistical analysis}

Descriptive statistical analyses were used to summarize the result (mean standard deviation [SD]). Analysis of association (Chi squared test $\chi^{2}$ ) and multivariate logistic regression were used to analyze data using statistical package for social science software (SPSS version 23). The odds ratio (OR) and 95\% confidence interval $(\mathrm{CI})$ were executed to assess the independent risk factors for the development of AKI. $P$ value $<0.05$ was considered statistically significant.

\section{Results}

\section{Description of the study population}

A total of 187 subjects were admitted to ICU at Fedail hospital during the study period. Of these $(105,56.2 \%)$ with a mean age of $61 \pm 3.5$ years have met the inclusion criteria. Slightly more than half of the subjects were males $(59,56.2 \%)$. The majority of the subjects have had normal kidney functions $(64,61.0 \%)$ throughout the study while $(41,39.0 \%)$ have had developed AKI during their stay at the ICU. The majority of subjects who have developed AKI were males $(25,60.9 \%)$ with age greater than 60 years $(\mathrm{n}=32,52.5 \%)$. The severity grading of AKI was mainly staged $1(45.5 \%)$ and stage $2(54.5 \%)$. The distribution of subjects' age, age groups, and gender dichotomized on AKI and non-AKI was presented in Table 1 . 
Table 1 The characteristics and comorbidities of the subjects (105) admitted to the ICU dichotomized for non AKI (64) and AKI (41)

\begin{tabular}{|c|c|c|c|}
\hline Variable parameter & Non AKI N (\%) & $\begin{array}{l}\text { Developed AKI post ICU } \\
\text { admission } \mathrm{N}(\%)\end{array}$ & Total N (\%) \\
\hline \multicolumn{4}{|l|}{ Gender } \\
\hline Female & $30(65.2)$ & $16(34.8)$ & $46(43.8)$ \\
\hline Male & $34(57.6)$ & $25(42.4)$ & $59(56.2)$ \\
\hline \multicolumn{4}{|l|}{ Age (years) } \\
\hline$(18-28)$ & $4(80.0)$ & $1(20.0)$ & $5(4.7)$ \\
\hline$(29-39)$ & $7(70.0)$ & $3(30.0)$ & $10(9.5)$ \\
\hline$(40-49)$ & $6(66.7)$ & $3(33.3)$ & $9(8.5)$ \\
\hline$(50-60)$ & $16(80.0)$ & $4(20.0)$ & $20(19.0)$ \\
\hline$>60$ & $29(47.5)$ & $32(52.5)$ & $61(58.1)$ \\
\hline \multicolumn{4}{|l|}{ Comorbidities } \\
\hline Hypertension & $22(48.8)$ & $23(51.2)$ & $45(42.8)$ \\
\hline Diabetes mellitus & $17(46.0)$ & $20(54.0)$ & $37(35.2)$ \\
\hline Chronic cardiovascular diseases & $8(29.7)$ & $19(70.3)$ & $27(25.7)$ \\
\hline Pre-existing CKD & $5(21.7)$ & $18(78.3)$ & $23(22.0)$ \\
\hline Respiratory diseases & $10(66.7)$ & $5(33.3)$ & $15(14.3)$ \\
\hline Cancer & $6(42.8)$ & $8(57.2)$ & $14(13.3)$ \\
\hline Liver cirrhosis/liver failure & $3(42.8)$ & $4(57.2)$ & $7(6.7)$ \\
\hline HIV infection & $0(0)$ & $1(100.0)$ & $1(0.9)$ \\
\hline \multirow{2}{*}{$\begin{array}{l}\text { Serum creatinine at admission to ICU } \\
(\mathrm{mg} / \mathrm{dl}) \text { : mean }(\mathrm{SD}) \text { and (range) }\end{array}$} & $0.82(0.29)$ & $1.2(0.44)$ & \multirow[t]{2}{*}{ NA } \\
\hline & Range (0.2- 1.2) & Range (0.3-2.2) & \\
\hline \multirow{2}{*}{$\begin{array}{l}\text { Serum creatinine at diagnosis of AKI } \\
(\mathrm{mg} / \mathrm{dl}): \text { mean }(\mathrm{SD}) \text { and (range) }\end{array}$} & NA & $2.8(1.5)$ & \multirow[t]{2}{*}{ NA } \\
\hline & & Range (2.2-10) & \\
\hline
\end{tabular}

$A K I$ Acute kidney injury, $I C U$ intensive care unit, $C K D$ chronic kidney disease, $H I V$ human immune virus, $N$ number/frequency, $N A$ not applicable, $S D$ standard deviation, $\%$ percent
Within all subjects, hypertension was the most frequent comorbidity $(45,42.8 \%)$, followed by diabetes mellitus ( 37 , $35.2 \%)$, chronic cardiovascular diseases $(27,25.7 \%)$, preexisting CKD (23, 22.0\%), and respiratory diseases (15, $14.3 \%$ ), with subjects having more than one comorbidity. Within the subjects who have had developed AKI, hypertension was most frequent comorbidity $(23,56.0 \%)$, followed by diabetes mellitus $(20,48.8 \%)$, chronic cardiovascular diseases $(19,46.3 \%)$ and pre-existing CKD $(18,44.0 \%)$ (Table 1).

Subjects in this study were taking calcium channel blockers $(18,43.9 \%)$, antibiotics $(15,36.6 \%)$ such as vancomycin $(11,26.8 \%)$ and others (e.g. ciprofloxacin, rifampin, acyclovir, amikacin), thiazide diuretics $(14,34.1 \%)$, angiotensinconverting enzyme (ACE) inhibitors/angiotensin receptor blockers (ARBs; $[19,22.0 \%])$, chemotherapy $(8 ; 19.5 \%)$, non-steroidal anti-inflammatory drugs [NSAIDs] $(6,14.6 \%)$, and radiocontrast media $(3,7.3 \%)$.

Some of the above-mentioned medications have been either added or continued during admission to ICU were examined as possible reasons for AKI in the study population. The serum creatinine levels (means $\pm \mathrm{SD}$ ) of subjects who have had developed AKI post-admission to ICU, was $1.2(0.44$, range [0.3-2.2]) at baseline, while it was $2.8(1.5$, range [2.2-10]) at the diagnosis of AKI.
The main reasons for admission to the ICU were sepsis $(n=62,59.0 \%)$, respiratory diseases $(43,41.0 \%)$, and neurological disorders $(32,30.4 \%)$. The main etiological reasons for the development of AKI were: sepsis $(33,80.0 \%)$, respiratory diseases $(19,46.3 \%)$ and hypovolemic shock (13, $31.7 \%$ ) (Table 2).

The incidence of AKI in our sample was 39.0\%, whereby 41 subjects have had developed AKI during their admission to the ICU. The risk factors for developing AKI were: gender; age $>60$ years; sepsis; hypovolemia; hypertension; diabetes mellitus, chronic heart diseases; pulmonary disorder, cancer; mechanical ventilation and renal replacement therapy (RRT). The significant predictors for developing AKI in subjects admitted to the ICU were: sepsis (OR 7.5 [95\% CI 3-19.7]; $P=0.001$ ); hypovolemia (OR 5.1 [95\% CI 2-15.7]; $P=0.001$ ); chronic cardiovascular diseases (OR 3.4 [95\% CI 1.2-9.4]; $P=0.017$ ); age $>60$ years (OR 2.7 [95\% CI 1.2-6.3]; $P=0.018$ ); diabetes mellitus (OR 2.6 [95\% CI 1.2-6]; $P=0.02$ ); hypertension (OR 2.4 [95\% CI 1.2-5.4]; $P=0.028$ ); and RRT (OR 0.2 [95\% CI $0.15-0.3$ ]; $P=0.001$ ). The predictors and respective odds ratio for the development of AKI were presented in Table 3.

The majority of subjects have required mechanical ventilation during their stay in the ICU $(77,73.4 \%)$. There were $(31,75.6 \%)$ of subjects with AKI have had required 
Table 2 Reasons for admission to the ICU dichotomized for non AKI (64) and AKI (41) subjects

\begin{tabular}{lccc}
\hline Reason for admission to ICU & Non AKI N (\%) & $\begin{array}{l}\text { Developed AKI post admis- } \\
\text { sion to ICU N (\%) }\end{array}$ & Total N (\%) \\
\hline Sepsis and septic shock & $29(57.0)$ & $33(64.7)$ & $62(59.0)$ \\
Respiratory diseases & $24(42.0)$ & $19(34.0)$ & $43(41.0)$ \\
Neurological disorder & $24(60.0)$ & $8(20.0)$ & $32(30.4)$ \\
Postsurgical procedure & $16(66.6)$ & $8(33.4)$ & $24(22.8)$ \\
Cardiovascular complications & $13(36.0)$ & $10(28.0)$ & $23(22.0)$ \\
Hypovolemic shock & $10(28.0)$ & $13(36.0)$ & $23(22.0)$ \\
Liver failure & $6(46.0)$ & $7(54.0)$ & $30(28.5)$ \\
*Others & $14(46.7)$ & $16(53.3)$ & \\
\hline
\end{tabular}

$A K I$ Acute kidney injury, ICU intensive care unit, $N$ number/frequency, \% percent

*Others minor reasons were: Metabolic acidosis; diabetic ketoacidosis, anemia, hepatospleenomegaly, rhabdomyolysis, chronic myelogenous leukemia, hepato-renal syndrome, hyperglycemic hypersmolar nonketotic coma, malaria, multi organ dysfunction, burn, cellulitis, corona virus, respiratory failure, disseminated Intravascular coagulopathies, Gillian Barre Syndrome (GBS), gastrointestinal, pancreatitis
Table 3 Multivariate analyses for risk factors (OR, 95\% CI) and predictors for the development of AKI in subjects (105) admitted to the ICU (AKI cohort)

\begin{tabular}{lccl}
\hline Variable & $\begin{array}{c}\text { Odds } \\
\text { ratio } \\
\text { (OR) }\end{array}$ & $95 \%$ CI & $P$ value \\
\hline Gender & 1.4 & $0.6-31$ & 0.43 \\
Age (>60 years) & 2.7 & $1.2-6.3$ & $0.018^{*}$ \\
Sepsis & 7.5 & $3-19.7$ & $0.001^{*}$ \\
Hypovolemia (volume depletion) & 5.1 & $2-15.7$ & $0.001^{*}$ \\
Hypertension & 2.4 & $1.2-5.4$ & $0.028^{*}$ \\
Diabetes mellitus & 2.6 & $1.2-6$ & $0.02^{*}$ \\
Chronic cardiovascular diseases & 3.4 & $1.2-9.4$ & $0.017^{*}$ \\
Respiratory diseases & 0.7 & $0.2-2.3$ & 0.62 \\
Cancer & 1.2 & $0.3-3.7$ & 0.75 \\
Mechanical ventilation & 1.2 & $0.4-2.9$ & 0.67 \\
RRT & 0.2 & $0.15-0.3$ & $0.001^{*}$ \\
\hline
\end{tabular}

$A K I$ Acute kidney injury, $C I$ confidence interval, $I C U$ intensive care unit, $O R$ odds ratio, $R R T$ renal replacement therapy

$* P<0.5$

mechanical ventilation; versus $(46,72.0 \%)$ with non-AKI. $53(68.8 \%)$ of subjects had died from those who have had received mechanical ventilation. There were $(22,53.7 \%)$ from the AKI group have had received RRT of which 20 $(91.0 \%)$ have died. There were statistically significant associations between mechanical ventilation $(P=0.04)$, RRT $(P=.001)$, and mortality. The length of hospital stay for subjects who have developed AKI was (6.7 \pm 3.8 ; [range 2-17]) versus those with non-AKI (4.1 \pm 3.1 ; [range $1-14), P=0.1$. The mortality rate was very high in subjects who have had developed AKI $(36,87.8 \%)$, corresponding to an overall mortality rate of $62.9 \%$ (Table 4 ).
Table 4 The medications used as possible predisposing factors for developing AKI in subjects (105) admitted to ICU (AKI cohort)

\begin{tabular}{lc}
\hline Predisposing factor for developing AKI & $\mathrm{N}(\%)$ \\
\hline Diuretics & $14(34.1)$ \\
Vancomycin & $11(26.8)$ \\
ACEI/ARBs & $9(22.0)$ \\
Chemotherapy & $8(19.5)$ \\
NSAIDs & $6(14.6)$ \\
Radio-contrast media & $3(7.3)$ \\
Amikacin & $3(7.3)$ \\
\hline
\end{tabular}

The above mentioned predisposing factors were captured from the medication chart of AKI cohort. However, there was no direct evident association between the use of the above drugs and the incidence of AKI

$A K I$ Acute kidney injury, ICU intensive care unit, ACEI/ARBs angiotensin converting enzyme inhibitors/angiotensin receptor blockers, NSAIDs non-steroidal anti-inflammatory drugs, $N$ number/frequency, $\%$ percent

\section{Discussion}

\section{The current study findings}

The development of AKI was very common among subjects admitted to the ICU at our hospital. The current study was the first of its kind in Sudan to report the development of AKI in the ICU setting. It has examined the incidence, risk factors and mortality outcomes of subjects with AKI developed during their admission to the intensive care unit at Fedail Hospital, Khartoum, Sudan. The main finding of the study was the high incidence of AKI in the study population $(39.0 \%)$. The second finding was the predictors for developing AKI in subjects admitted to the ICU. The major significant predictors for the development of AKI in 
the ICU were: sepsis; hypovolemia; chronic cardiovascular diseases; age $>60$ years; diabetes mellitus; hypertension; and RRT. There is a possibility that some of these predictors might be cofounders such as cardiovascular diseases (cardio-renal syndrome) and RRT. Furthermore, due to the study design of observational nature, it was not possible to eliminate the presence of other confounders such as the hepato-renal syndrome and the cardio-renal syndrome. The age $>60$ years predicts the development of AKI, which might be attributed to the associated comorbidities.

The third finding was relevant to the longer length of ICU stay for subjects who have developed AKI $(6.7 \pm 3.8$; [range 2-17]) versus those with non-AKI (4.1 \pm 3.1 ; [range 1-14), $P=0.1$. The difference in the mean value of the length of stay may be attributed to the prolonged hospitalization needed for the management of the subjects with AKI, as there was greater mortality in those with AKI, may have been even longer had those patients survived.

The fourth finding was the very high absolute mortality rate of $87.8 \%$, which might be related to poorly coordinated care provided to our population.

\section{Comparison between the findings of the current study and other similar studies}

In the current study, the incidence of AKI (39.0\%) was less than that reported in a large Chinese cohort study [14] conducted in 30 ICUs where the incidence of AKI was $51.0 \%$. This variation can be attributed to the characteristics differences between the two populations and the criteria used for the classification of AKI. The Chinese study has excluded nearly 6000 subjects (3107 participants were included in the final analysis among the 9049 subjects admitted to the participating ICUs during the study period) which might have affected the reported mortality. The incidence of AKI has included stage one (23.1\%), stage $2(11.8 \%)$, and stage $3(15.7 \%)$ [14]. However, in our current study, the severity grading of AKI was mainly staged 1 (45.5\%) and stage 2 $(54.5 \%)$.

Marwa et al. [15]; have conducted a large retrospective cohort (6769 hospitalized subjects), a 1 year study in a tertiary teaching hospital (Soba University hospital) at Khartoum, Sudan. The incidence of AKI in this study was 5.7\% compared to $39.0 \%$ in our study and the mortality rate was $31.2 \%$ compared to $87.8 \%$ in our study. The large variations between the two studies may be attributed to the variations in the study design (the retrospective vs. prospective), the quality of care, and differences between the two settings from where data was generated (versus all hospital wards versus ICU) [15].

An Egyptian multicenter prospective cohort study [16] was conducted in four Alexandria teaching hospitals, has reported that $39.6 \%$ of subjects have had AKI during their admission to the ICU. This was very similar to the findings of our study (39.0\%). The preponderance of males in the AKI group of subjects was evident in both the Sudanese and the Malaysian studies [15, 17]. Both the Sudanese and the Egyptian studies [15, 16] have reported sepsis and volume depletion as the etiological confounded reasons for AKI.

The current study has reported that the major significant risk factors and predictors for the development of AKI in the ICU were: gender; age $>60$ years; hypertension; and diabetes mellitus. Similar findings have been revealed in the large retrospective study at Suba teaching hospital in Sudan [15]. In the current study the severity grading of AKI was mainly staged $1(45.5 \%)$ and stage $2(54.5 \%)$, which were nearly similar to the Egyptian study [16]; however; they were different from the Sudanese study [15], where the majority were stage $3(47.9 \%)$.

A recent systematic review and meta-analysis of twentyfour observational studies performed in trauma subjects admitted to the ICU have reported the incidence of AKI of $24.0 \%$ [18]. Similar to our study some of the reported risk factors (high age, hypertension, diabetes mellitus, shock, and sepsis) have been recognized from this systematic review. Similar findings of the length of hospital stay 6 (4.0-7.9) days have been reported but with lower absolute mortality in subjects with AKI (27.0\%) [18].

In Thailand, the largest prospective observational multicenter study (17 ICU centers) of AKI in Southeast Asia (SEA), reported AKI in 2471 of 4668 subjects (52.9\%). AKI was classified as stage 1 in (7.5\%), stage 2 in (16.5\%), and Stage 3 in (28.9\%). Similar to our study older age and cardiovascular-related diseases were reported as risk factors for developing AKI [19]. A multinational (4 countries, North American, Europe, and Australia), multicenter (six centers) prospective observational cohort study in the ICU $(15,132$ subjects), 32.0\% had developed AKI (OR, 2.57-6.04, $P<0.001)$ and hospital mortality was $27.0 \%$ (OR, 1.13-2.20, $P<0.001$ ) [20]. The variations on the odds ratio reflect the wide variability between centers in the reported incidences and mortality of AKI.

The clinical presentation of lab values is very crucial to monitor closely and timely in subjects admitted to the ICU. The correction of any abnormal lab values higher than baselines such as serum creatinine, blood urea nitrogen, bicarbonate, chloride, and micro-albuminuria is deemed important. It has been reported in a large study that higher serum chloride concentrations are associated with AKI in unselected critically ill subjects, due to its impact on clearance [21]. Furthermore, another study by the same author has reported that micro-albuminuria can predict the development of AKI in critically ill septic subjects [22].

Recently, RRT has been reported to be an independent risk factor for mortality in AKI [23] and does not reverse the negative impact of AKI [24]. Furthermore, a multicenter 
randomized controlled trial in subjects with severe AKI and sepsis showed that a 'watch and wait' approach resulted in less use of RRT and did not increase mortality [25]. Furthermore, positive fluid balance in subjects on RRT independently impacted the outcomes [26, 27].

Healthcare facilities need to develop strict protocols to prevent, monitor, diagnose, report, and follow up AKI in the ICU. Particular emphasis should be fostered to identify early signs of AKI in ICU to deploy earlier management based on strict protocols and guidelines. The presence of the clinical pharmacist within the multidisciplinary team of ICU is needed to set controlled maneuvers for the utility of medications, laboratory monitoring for serum creatinine, and contribute to the early prediction of the development of AKI.

The implications of the current study for future research might be expressed in the need of examining AKI in multicenter ICU studies with prospective follow up study design to prevent conversion to CKD. Moreover, more details on the role of RRT on long term clinical outcomes and survival are required. Furthermore, the quality of life of subjects with AKI needed to be explored and assessed with standard validated tools. The discharge care of subjects with AKI need further investigations and deserve planned discharge with follow up and care process (continuity of care). Populationbased studies are of great importance in establishing strategic health planning. Therefore, a more robust assessment of predictors for the development of AKI in ICU deserves special consideration in the national-wide scope.

\section{Limitations of the current study}

The main limitation of the current study was the small sample size. The nature of our study, particularly the data reported from the clinical records may have resulted in some bias. The other limitation may be related to the nature of the hospital, as selection bias may have affected the intake of cases, which may not be representative of AKI subjects in all Khartoum state. We were not able to examine the role of RRT, the timing, the modality type of the RRT, and the recovery of renal function in our sample.

\section{Conclusion}

The main finding of the current study was relevant to the high incidence of AKI in subjects admitted to the ICU. The main etiological risk factors that have contributed to the development of AKI in our sample were sepsis and hypovolemia. The major significant predictors for the development of AKI in the ICU were: sepsis; hypovolemia; chronic cardiovascular diseases; age > 60 years; diabetes mellitus; hypertension; and
RRT. The study has revealed that the development of AKI in subjects admitted to the ICU was associated with increased length of hospital stay and very high absolute mortality. It is highly recommended that subjects admitted to the ICU should be stratified for risk of AKI according to their susceptibilities and exposures.

Acknowledgements We would like to thank the staff and admin at Fedail hospital for their assistance in conducting the study.

Funding The authors declare that no funding was received in full or partly towards this study. No funding or financial support was obtained to conduct this study.

Data availability There was no any associated data.

Conflicts of interest All authors declare no conflicts of interest.

Consent for publication We declare our consent for the publication of our article.

\section{Appendix 1: The KDIGO staging for AKI severity (AKI is staged for severity according to the following criteria)}

\begin{tabular}{|c|c|c|}
\hline Stage & $\begin{array}{l}\text { Serum creatinine } \\
\text { (SCr) }\end{array}$ & Urine output \\
\hline 1 & $\begin{array}{l}1.5-1.9 \text { times } \\
\text { baseline } \\
\text { or } \geq 0.3 \mathrm{mg} / \\
\mathrm{dL} \text { increase } \\
(\geq 26.5 \mu \mathrm{mol} / \mathrm{L}) \\
\text { increase }\end{array}$ & $\begin{array}{l}<0.5 \mathrm{~mL} / \mathrm{kg} / \mathrm{h} \text { for } \\
\quad 6-12 \mathrm{~h}\end{array}$ \\
\hline 2 & 2-2.9 times baseline & $\begin{array}{l}<0.5 \mathrm{~mL} / \mathrm{kg} / \mathrm{h} \text { for } \\
\geq 12 \mathrm{~h}\end{array}$ \\
\hline 3 & $\begin{array}{l}3 \text { times baseline } \\
\text { or increase in } \mathrm{SCr} \\
\text { to } \geq 4 \mathrm{mg} / \mathrm{dL} \\
(\geq 353.6 \mu \mathrm{mol} / \mathrm{L}) \\
\text { or initiation of } \\
\text { renal replace- } \\
\text { ment therapy in } \\
\text { patients } \geq 18 \text { years, } \\
\text { decrease in eGFR } \\
\text { to }<35 \mathrm{~mL} / \mathrm{min} \\
\text { per } 1.73 \mathrm{~m}^{2}\end{array}$ & $\begin{array}{l}<0.3 \mathrm{~mL} / \mathrm{kg} / \mathrm{h} \text { for } \\
\geq 24 \mathrm{~h} \\
\text { or anuria for } \geq 12 \mathrm{~h}\end{array}$ \\
\hline
\end{tabular}

$A K I$ Acute kidney injury, $e G F R$ estimated glomerular filtration rate, $K D I G O$ Kidney Disease Improving Global Outcomes, $\mathrm{SCr}$ serum creatinine

Reference: [1] 


\section{Appendix 2: Classification for AKI by various criteria}

\begin{tabular}{|c|c|c|c|c|}
\hline Stage & KDIGO* & RIFLE** & $\mathrm{AKIN}^{* * *}$ & Urine output \\
\hline Stage 1 & $\begin{array}{l}\text { Increase in } \\
\mathrm{SCr} \text { of } \\
0.3 \mathrm{mg} / \\
\mathrm{dL} \\
\text { (within } \\
48 \mathrm{~h} \text { ) } \\
\text { or } \times 1.5 \\
\text { (within } \\
7 \text { days) }\end{array}$ & $\begin{array}{c}\text { Increase in } \\
\text { SCr } \times 1.5 \\
\text { (within } \\
7 \text { days) }\end{array}$ & $\begin{array}{l}\text { Increase in } \\
\mathrm{SCr} \text { of } \\
0.3 \mathrm{mg} / \\
\mathrm{dL} \text { or } \\
>\times 1.5 \\
\text { (within } \\
48 \mathrm{~h} \text { ) }\end{array}$ & $\begin{array}{l}\text { Urine output } \\
\text { of }<0.5 \mathrm{mg} / \\
\mathrm{kg} / \mathrm{h} \\
\text { for }>6 \mathrm{~h}\end{array}$ \\
\hline Stage 2 & $\begin{array}{c}\text { Increase in } \\
\mathrm{SCr} \times 2\end{array}$ & $\begin{array}{c}\text { Increase in } \\
\mathrm{SCr} \times 2\end{array}$ & $\begin{array}{c}\text { Increase in } \\
\mathrm{SCr} \times 2\end{array}$ & $\begin{array}{l}\text { Urine output } \\
\text { of }<0.5 \mathrm{mg} / \\
\mathrm{kg} / \mathrm{h} \text { for } \\
>12 \mathrm{~h}\end{array}$ \\
\hline Sage 3 & $\begin{array}{l}\text { Increase in } \\
\mathrm{SCr} \times 3 \\
\text { or above } \\
4.0 \mathrm{mg} / \\
\mathrm{dL}\end{array}$ & $\begin{array}{l}\text { Increase in } \\
\mathrm{SCr} \times 3 \\
\text { or above } \\
4.0 \mathrm{mg} / \mathrm{dL}\end{array}$ & $\begin{array}{l}\text { Increase in } \\
\text { SCr } \times 3 \\
\text { or above } \\
4.0 \mathrm{mg} / \\
\mathrm{dL}\end{array}$ & $\begin{array}{l}\text { Urine output } \\
\text { of }<0.3 \mathrm{mg} / \\
\mathrm{kg} / \mathrm{h} \text { for } \\
>24 \mathrm{~h} \text { or } \\
\text { anuria for } \\
>12 \mathrm{~h}\end{array}$ \\
\hline $\begin{array}{l}\text { RIFLE- } \\
\text { Loss }\end{array}$ & - & $\begin{array}{l}\text { Need for } \\
\text { RRT for } \\
>4 \text { weeks }\end{array}$ & - & - \\
\hline $\begin{array}{l}\text { RIFLE- } \\
\text { End } \\
\text { stage }\end{array}$ & - & $\begin{array}{l}\text { Need for } \\
\text { RRT for } \\
>3 \text { months }\end{array}$ & - & - \\
\hline
\end{tabular}

AKIN***: AKI: Acute Kidney Injury Network; KDIGO*: Kidney Disease Improving Global Outcomes; RIFLE**: Risk, Injury, Failure, Loss, and End-stage renal disease; SCr: serum creatinine

References: $[1,28,29]$

\section{Appendix 3: Definitions of AKI}

\section{KIDGO:}

Increase in $\mathrm{SCr}$ by $\geq 0.3 \mathrm{mg} / \mathrm{dL}$ within $48 \mathrm{~h}$ or to $\geq 1.5$ times baseline, known or presumed to have occurred within the prior 7 days.

\section{RIFLE:}

Increase in $\mathrm{SCr} \times 1.5$ or GFR decrease $>25 \%$.

\section{Akin:}

Increase in $\mathrm{SCr} \geq 0.3 \mathrm{mg} / \mathrm{dL}$ or increase $\geq 150-200 \%$ (1.5- to twofold) from baseline within $48 \mathrm{~h}$.

\section{References}

1. Kellum JA, Lameire N, Aspelin P, Barsoum RS, Burdmann EA, Goldstein SL, et al. Kidney disease: improving global outcomes (KDIGO) acute kidney injury workgroup. KDIGO clinical practice guideline for acute kidney injury. Kidney Int Suppl. 2012;2(1):1-138. https://doi.org/10.1038/kisup.2012.1.

2. Lameire NH, Bagga A, Cruz D, De Maeseneer J, Endre Z, Kellum JA, et al. Acute kidney injury: an increasing global concern. Lancet. 2013;382:170-9.

3. Lewington AJ, Cerdá J, Mehta RL. Raising awareness of acute kidney injury: a global perspective of a silent killer. Kidney Int. 2013;84:457-67.

4. Susantitaphong P, Cruz DN, Cerda J, Abulfaraj M, Alqahtani F, Koulouridis I, et al. Acute Kidney Injury Advisory Group of the American Society of Nephrology. World incidence of AKI: a meta-analysis. Clin J Am Soc Nephrol. 2013;8:1482-93.

5. Wonnacott A, Meran S, Amphlett B, Talabani B, Phillips A. Epidemiology and outcomes in community-acquired versus hospitalacquired AKI. Clin J Am Soc Nephrol. 2014;9:1007-14.

6. Wang Y, Wang J, Su T, Qu Z, Zhao M, Yang L, et al. China consortium. Community-acquired acute kidney injury: a nationwide survey in China. Am J Kidney Dis. 2017;69:647-57.

7. Santos PR, Monteiro DLS. Acute kidney injury in an intensive care unit of a general hospital with emergency room specializing in trauma: an observational prospective study. BMC Nephrol. 2015; $16: 1$.

8. Kane-Gill SL, Sileanu FE, Murugan R, Trietley GS, Handler SM, Kellum JA. Risk factors for acute kidney injury in older adults with critical illness: a retrospective cohort study. Am J Kidney Dis. 2015;65(6):860-9.

9. Linder A, Fjell C, Levin A, Walley KR, Russell JA, Boyd JH. Small acute increases in serum creatinine are associated with decreased long-term survival in the critically ill. Am J Respir Crit Care Med. 2014;189:1075-81.

10. Bellomo R, Kellum JA, Ronco C. Acute kidney injury. Lancet. 2012;380:756-66.

11. Chawla LS, Eggers PW, Star RA, Kimmel PL. Acute kidney injury and chronic kidney disease as interconnected syndromes. N Engl J Med. 2014;371:58-66.

12. Mehta RL, Cerdá J, Burdmann EA, Tonelli M, García-García G, Jha V, et al. International Society of Nephrology's 0by 25 initiative for acute kidney injury (zero preventable deaths by 2025): a human rights case for nephrology. Lancet. 2015;385(9987):2616-43.

13. Singer M, Deutschman CS, Seymour CW, Shankar-Hari M, Annane D, Bellomo R, et al. The third international consensus definitions for sepsis and septic shock (Sepsis-3). JAMA. 2016;315:801-10.

14. Jiang L, Zhu Y, Luo X, Wen Y, Du B, Wang M, et al. Epidemiology of acute kidney injury in intensive care units in Beijing: the multi-center BAKIT study. BMC Nephrol. 2019;20(1):468.

15. Osman M, Shigidi M, Ahmed H, Abdelrahman I, Karrar W, Elhassan E, et al. Pattern and outcome of acute kidney injury among Sudanese adults admitted to a tertiary level hospital: a retrospective cohort study. Pan Afr Med J. 2017;28(1):165.

16. Abd ElHafeez S, Tripepi G, Quinn R, Naga Y, Abdelmonem S, AbdelHady M, et al. Risk, predictors, and outcomes of acute kidney injury in patients admitted to intensive care units in Egypt. Sci Rep. 2017;7:17163.

17. Ab Hamid SA, Wan Adnan NA, Naing NN, Adnan AS. Acute kidney injury in intensive care unit, Hospital University Sains Malaysia: a descriptive study. Saudi J Kidney Dis Transpl. 2018;29(5):1109-14.

18. Søvik S, Isachsen MS, Nordhuus KM, Tveiten CK, Eken T, Sunde $\mathrm{K}$, et al. Acute kidney injury in trauma patients admitted to the 
ICU: a systematic review and meta-analysis. Intensive Care Med. 2019;45(4):407-19.

19. Srisawat N, Kulvichit W, Mahamitra N, Hurst C, Praditpornsilpa $\mathrm{K}$, Lumlertgul N, et al. The epidemiology and characteristics of acute kidney injury in the Southeast Asia intensive care unit: a prospective multicentre study. Nephrol Dial Transpl. 2019;1-1.

20. Srisawat N, Sileanu FE, Murugan R, Bellomod R, Calzavacca $\mathrm{P}$, Cartin-Ceba R, et al. Variation in risk and mortality of acute kidney injury in critically ill patients: a multicenter study. Am J Nephrol. 2015;41(1):81-8.

21. Zhang Z, Xu X, Fan H, Li D, Deng H. Higher serum chloride concentrations are associated with acute kidney injury in unselected critically ill patients. BMC Nephrol. 2013;14:235.

22. Zhang Z, Lu B, Ni H, Sheng X, Jin N. Microalbuminuria can predict the development of acute kidney injury in critically ill septic patients. J Nephrol. 2013;26(4):724-30.

23. Elseviers MM, Lins RL, Van der Niepen P, Hoste, E., Malbrain, M.L., Damas, P., et al. Renal replacement therapy is an independent risk factor for mortality in critically ill patients with acute kidney injury. Crit Care. 2010;14:R221.

24. Hoste E, Bagshaw S, Bellomo R, Cely CM, Colman R, Cruz $\mathrm{DN}$, et al. Epidemiology of acute kidney injury in critically ill patients: the multinational AKIEPI study. Intensive Care Med. 2015;41:1411-23.

25. Barbar SD, Clere-Jehl R, Bourredjem A, Hernu R, Montini F, Bruyère $R$, et al. Timing of renal replacement therapy in patients with acute kidney injury and sepsis. N Engl J Med. 2018;379:1431-42.
26. Bellomo R, Cass A, Cole L, Finfer S, Gallagher M, Lee J, et al. An observational study fluid balance and patient outcomes in the randomized evaluation of normal vs. augmented level of replacement therapy trial. Crit Care Med. 2012;40(6):1753-60.

27. Vaara ST, Korhonen AM, Kaukonen KM, Nisula S, Inkinen O, Hoppu S, et al. Fluid overload is associated with an increased risk for 90-day mortality in critically ill patients with renal replacement therapy: data from the prospective FINNAKI study. Crit Care. 2012;16:R197.

28. Bellomo R, Ronco C, Kellum JA, Mehta RL, Palevsky P. Acute renal failure-definition, outcome measures, animal models, fluid therapy and information technology needs: the second international consensus conference of the acute dialysis quality initiative (ADQI) group. Crit Care. 2004;8:204-12.

29. Mehta RL, Kellum JA, Shah S, Molitoris BA, Ronco C, Warnock DG, et al. Acute kidney injury network: report of an initiative to improve outcomes in acute kidney injury. Crit Care. 2007;11:R31.

Publisher's Note Springer Nature remains neutral with regard to jurisdictional claims in published maps and institutional affiliations. 